\title{
Three-year monitoring of atmospheric PCBs and PBDEs at the Chinese Great Wall Station, West Antarctica: Levels, chiral signature, environmental behaviors and source implication
}

\author{
Pu Wang a , Yingming Li a , Qinghua Zhang a, b, c, *, Qinghua Yang ${ }^{\mathrm{d}}$, Lin Zhang ${ }^{\mathrm{d}}$, Fubin Liu ${ }^{\mathrm{d}}$, \\ Jianjie Fu ${ }^{\mathrm{a}}$, Wenying Meng ${ }^{\mathrm{a}, \mathrm{b}}$, Dou Wang ${ }^{\mathrm{a}, \mathrm{b}}$, Huizhong Sun ${ }^{\mathrm{a}}{ }^{\mathrm{b}}$, Shucheng Zheng ${ }^{\mathrm{a}, \mathrm{b}}$, \\ Yanfen Hao ${ }^{\mathrm{a}, \mathrm{b}}$, Yong Liang ${ }^{\mathrm{c}}$, Guibin Jiang ${ }^{\mathrm{a}, \mathrm{b}}$ \\ a State Key Laboratory of Environmental Chemistry and Ecotoxicology, Research Center for Eco-Environmental Sciences, Chinese Academy of Sciences, \\ Beijing 100085, China \\ ${ }^{\mathrm{b}}$ University of Chinese Academy of Sciences, Beijing 100049, China \\ ${ }^{\mathrm{c}}$ Institute of Environment and Health, Jianghan University, Wuhan 430056, China \\ d Key Laboratory of Research on Marine Hazards Forecasting, National Marine Environmental Forecasting Center, Beijing 100081, China
}

\section{H I G H L I G H T S}

- Atmospheric PCBs and PBDEs were measured at the Chinese Great Wall Station, West Antarctica during 2011 $-2014$.

- Nonracemic residues were commonly observed for chiral PCBs.

- Significant temperature dependence was observed for lighter PCBs (excluding PCB-11) in 2011 and 2012.

- The gas/particle partitioning behavior was evaluated by the steady-state-based model and equilibrium-state-based model.

\section{A R T I C L E I N F O}

\section{Article history:}

Received 14 September 2016

Received in revised form

10 November 2016

Accepted 11 November 2016

Available online 12 November 2016

\section{Keywords:}

PCBs

PBDES

Antarctic air

Chiral signature

Temperature dependence

Gas/particle partitioning

\section{G R A P H I C A L A B S T R A C T}

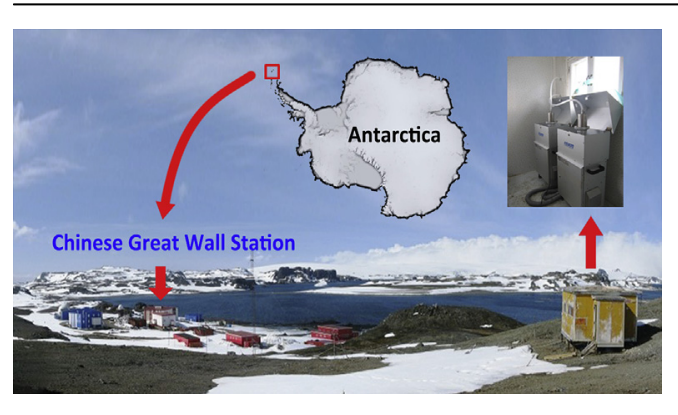

\footnotetext{
* Corresponding author. State Key Laboratory of Environmental Chemistry and Ecotoxicology, Research Center for Eco-Environmental Sciences, Chinese Academy of Sciences, Beijing 100085, China.

E-mail address: qhzhang@rcees.ac.cn (Q. Zhang).
} 
deriving from the technical formulations indicated a local source of Deca-BDE and photodegradation of higher brominated BDEs. The gas/particle partitioning of POPs was also evaluated and the newly developed steady-state-based model generally showed a better performance than the equilibrium-statebased model. However, the former still underestimated the partitioning of most PCBs $\left(\log K_{O A}<11\right)$ in particle phase, implying that further optimization is necessary when using it for those compounds with lower $\log K_{O A}$.

() 2016 Elsevier Ltd. All rights reserved.

\section{Introduction}

Persistent organic pollutants (POPs) have received great attention due to their adverse effects to human health and the environment. Ever since the chlorinated pesticides have been firstly detected in the Antarctic wildlife in the 1960's (Sladen et al., 1966), many studies have revealed that most POPs are ubiquitous in the environment and wildlife in the Polar Regions, which has aroused wide attention to their potential risks to the local ecosystem (Bengston Nash, 2011; Cabrerizo et al., 2013; Muir and de Wit, 2010).

Several regional and international monitoring programs have been conducted to systematically investigate POPs in the Polar Regions, such as the Arctic Monitoring and Assessment Programme (AMAP), United Nations Economic Commission for Europe, European Monitoring and Evaluation Programme (UNECE-EMEP) and Global Atmospheric Passive Sampling (GAPS) Network. Long-term monitoring results have indicated a generally declining tendency of many legacy POPs in the Arctic, especially in the ambient air (Hung et al., 2010, 2016; Kong et al., 2014). By contrast, less is known about the distribution and temporal trends of POPs in Antarctica, which is farther away from industrial sources relative to the Arctic. In recent years, Baek et al. (2011) first collected the data of polychlorinated biphenyl (PCBs) and organochlorine pesticides (OCPs) from both Arctic and Antarctic sampling sites using XAD-2 resin based passive air samplers (PAS), while no significant trends (2005-2007) were observed in King George Island, West Antarctica. Kallenborn et al. (2013) first conducted long-term monitoring of POPs (2007-2010) using a high-volume air sampler (HVAS) at the Norwegian Troll station in Dronning Maud Land, Antarctica. Similarly, no temporal trend was found for PCBs and OCPs. Dickhut et al. (2012), however, reported a significant decline of lighter polybrominated diphenyl ethers (PBDEs), i.e. BDE47, -99 , and -100 , in western Antarctic sea ice over the period of 2001-2007. Moreover, as reviewed by Bengston Nash (2011), there was an evident reduction of $\alpha$-hexachlocyclohexane $(\alpha-\mathrm{HCH})$ in the Antarctic Peninsula since the 1980's, while PCBs (PCB-28, -52, -101, $-138,-153$ and -180 ) did not demonstrate a consistent trend since the mid-1990's. These limited studies suggested that continuous long-term monitoring is warranted to demonstrate temporal trend of POPs in Antarctica, and action could be taken subsequently to protect this pristine area.

POPs can undergo long-range atmospheric transport (LRAT) to the remote areas, especially the Polar Regions. While several studies have revealed the impact of research stations on the surrounding areas in Antarctica (Hale et al., 2008; Wild et al., 2015). Moreover, as climate warms up, POPs deposited in sinks such as water, ice and soil are expected to revolatilize into the atmosphere (Nizzetto et al., 2010; Ma et al., 2011; Cabrerizo et al., 2013). Although Cabrerizo et al. (2013) demonstrated re-emission of POPs into the atmosphere from soils and snow in a sampling campaign in Livingston Island recently, the study on this phenomenon is still limited in the Antarctic area. Thus, it is worthwhile to further investigate the source and environmental behavior of POPs in Antarctica over a long time scale.

In this study, results from the three-year monitoring campaign (Jan 2011-2014) are presented on PCBs and PBDEs by HVAS in King George Island, West Antarctica. The aims were to investigate the levels and distribution pattern, temporal trend and their environmental behaviors including temperature dependence and gas/ particle partitioning in the west Antarctic air. The potential sources of these POPs were discussed in detail. The chiral signature of PCBs in air was also investigated, which gained insight into the transport and fate of POPs in this remote environment. As far as we know, this is the first comprehensive study involving chiral PCBs in the Antarctic atmosphere.

\section{Material and methods}

\subsection{Sample collection}

Chinese Antarctic Great Wall Station is located in King George Island, South Shetland Islands, West Antarctica, where there are some other research stations nearby including Chilean Frei Station and Russian Bellingshausen Station. Air samples were collected using HVAS (ECHO HiVol PUF, TCR TECORA, Italy) during Jan 2011-Jan 2014. The sampler was deployed in a cabin on a hilltop $\left(62^{\circ} 13^{\prime} 12^{\prime \prime} \mathrm{S}, 58^{\circ} 57^{\prime} 48^{\prime \prime} \mathrm{W}, 53 \mathrm{~m}\right.$ height above sea level), which is approximately $100 \mathrm{~m}$ away from the Great Wall Station (Fig. 1). The sampling period (7-day) was set at a one-week interval and approximately two samples were collected each month. The sampling flow was set as $200 \mathrm{~L} \mathrm{~min}^{-1}$ and the sample volume reached about $2000 \mathrm{~m}^{3}$. Glass fiber filter (GFF) and polyurethane foam (PUF) plugs were used to collect the particle-bound and gaseous POPs, respectively. The GFFs were weighed before and after sampling to obtain the total suspended particulates (TSP) amount. The GFF and PUF plug were wrapped with acetone-rinsed aluminum foil and sealed in ziplock bag after sampling. Under the complex meteorological condition with relative high humidity and salinity, some GFF samples were broken and a total of 65 paired samples were successfully obtained. The samples were stored in the freezer at $-20^{\circ} \mathrm{C}$ in the station and finally transported by air to the laboratory for target analysis.

\subsection{Sample preparation and analysis}

The analytical procedure followed our previous methods with some minor modifications (Wang et al., 2015; Zhang et al., 2015). Briefly, the samples were extracted by accelerated solvent extraction (ASE, ASE 300, Dionex, USA). The extracts were purified on silica gel column and $\mathrm{C}_{18}$-Solid Phase Extraction (SPE) column successively and finally concentrated for instrumental analysis. ${ }^{13} \mathrm{C}_{12}$-labeled surrogate standards and injection standards were spiked prior to extraction and instrumental analysis, respectively. High-resolution gas chromatography coupled with high-resolution mass spectrometer (HRGC/HRMS) was employed for PCBs and 


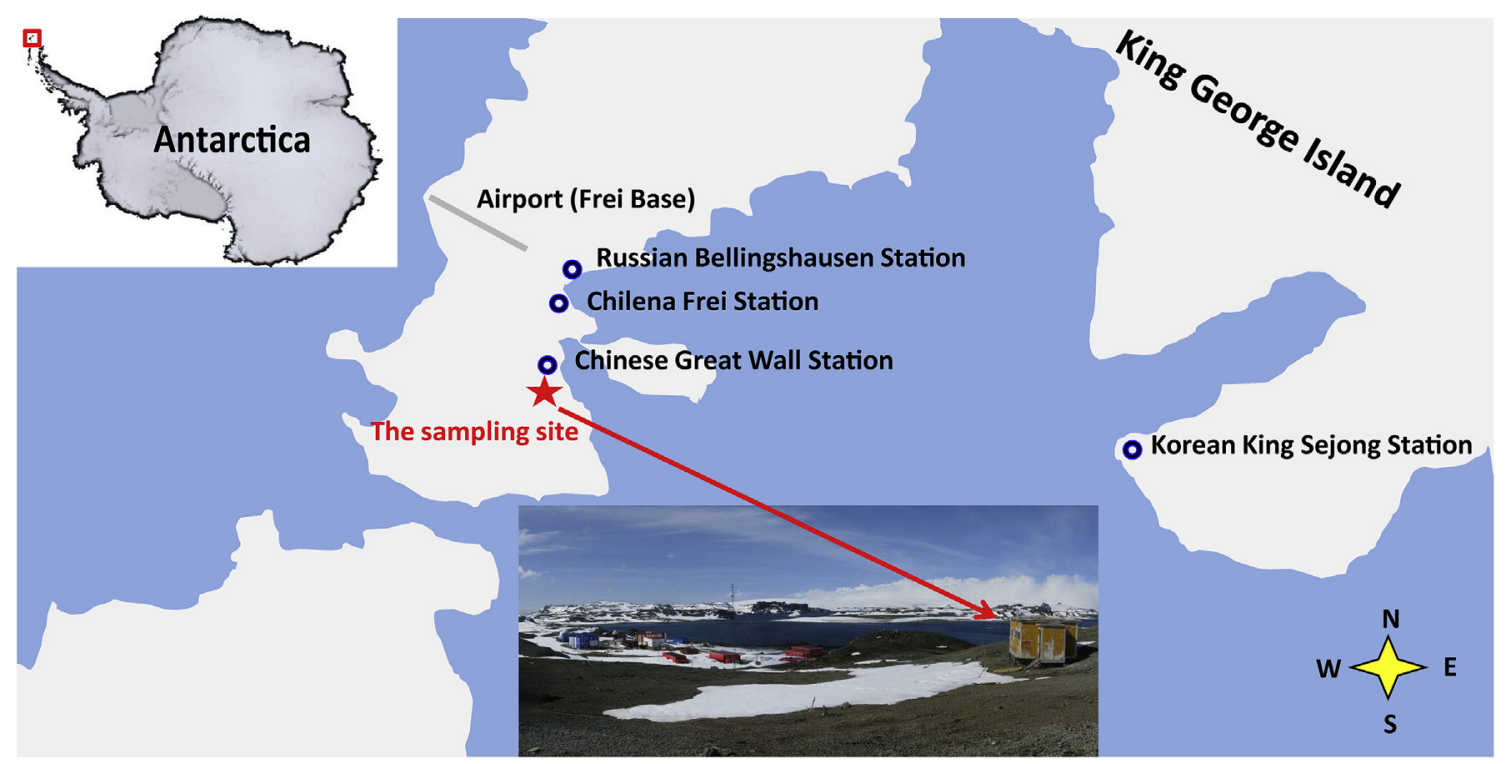

Fig. 1. The sampling site in King George Island, West Antarctica.

PBDEs analysis. The instrument was operated at a mass resolution $\geq 10,000$ with $\mathrm{EI}+$ mode for achiral compounds, while a lower resolution ( $\geq 5000$ ) was performed for chiral PCBs determination to ensure sufficient intensity of the target ions. The further details about sample extraction, cleanup and instrumental analysis are all given in the Supplementary material (SM).

\subsection{Quality assurance and quality control (QA/QC)}

All the target compounds were analyzed using isotope-dilution method and the performance criteria required for PCBs and PBDEs analysis followed the US EPA methods $1668 \mathrm{C}$ and $1614 .{ }^{13} \mathrm{C}$-labeled surrogated standards (68C-LCS and MBDE-MXG) were spiked in the samples for qualification and quantification, while ${ }^{13} \mathrm{C}$-labeled injection standards (68C-IS) were added for recovery calculation. The average recoveries of 68C-LCS and MBDE-MXG were $97 \pm 27 \%$ and $72 \pm 29 \%$, respectively. The limit of detection (LOD) was defined as the signal-to-noise ratio $(S / N)=3: 1$ and the isotopic ratios between the two monitoring ions were within $\pm 15 \%$ of the theoretical values. In this study, the LODs for PCBs and PBDEs in the samples were in the range of $0.00002-0.031 \mathrm{pg} \mathrm{m}^{-3}$ and $0.0002-0.64 \mathrm{pg} \mathrm{m}^{-3}$, respectively. Before the sampling, a breakthrough test was performed by using a second half PUF in series with the first PUF in January 2010 (the monthly average temperature was $1.8^{\circ} \mathrm{C}$ ), and the test procedure was the same as that for the real samples. None of the targets were found in the second half PUFs $(n=3)$. Furthermore, a set of field blanks were added to the field samples to control unintended contamination during storage and transport. Considering that all the samples were stored in one freezer at $-20^{\circ} \mathrm{C}$ in the station and transported back to the laboratory once a year, 1 field + travel blank was carried out per year. These blanks and laboratory blanks were routinely analyzed for quality control. Most compounds were detected below LOD, except PCB-28 and -118 at a relatively low level compared with those in the samples ( $<15 \%$ of concentration values). The reported concentrations of POPs were therefore not corrected for the blank levels.

For the chiral PCBs analysis, racemic standards were repetitively analyzed to determine the reproducibility of enantiomer fraction (EF) measurement. Average EF values in the racemic standards were $0.501 \pm 0.008,0.498 \pm 0.007,0.499 \pm 0.006,0.503 \pm 0.017$
$0.508 \pm 0.007$ for PCB-95, $-136,-149,-174$, and -176 , respectively. The $95 \%$ confidence intervals of these EF values were $0.495-0.508$, $0.492-0.504,0.494-0.504,0.489-0.518$ and $0.502-0.514$, respectively. If the EF values for an individual sample fell inside the range for the standard, it was interpreted as not significantly different from the racemic signature (Kurt-Karakus et al., 2005; Genualdi et al., 2009). The possible coelutions on CP-Chirasil-Dex CB column were also tested. A commercial formulation (Aroclor 1260, which contains more of high-chlorinated PCB congeners) was analyzed and no evident interferences were observed nearby the target chromatographic peaks.

\subsection{Meteorological parameters}

Automated weather system (MAWS201, HydroMetTM, Valsala, Finland) has been deployed to measure wind speed, wind direction and air temperature in the Great Wall Station. Wind-rose diagrams were constructed to determine the prevailing winds during the sampling periods. In addition, seven-day backward trajectories with a starting height of $50 \mathrm{~m}$ were simulated using HYSPLIT 4 (http://www.arl.noaa.gov/ready/hysplit4.html) to identify the origin and pathways of air masses at the sampling site. Backward trajectories were calculated at 00:00 UTC (Coordinated Universal Time) on the seventh day of each sampling period.

\section{Results and discussion}

\subsection{Meteorological conditions}

Temporal variations of air temperature and wind speed during the sampling period are shown in Fig. S1. The annual average air temperature and wind speed at the Chinese Great Wall Station from 2011 to 2013 were $-3.1{ }^{\circ} \mathrm{C}$ and $7.3 \mathrm{~m} \mathrm{~s}^{-1},-2.6{ }^{\circ} \mathrm{C}$ and $7.5 \mathrm{~m} \mathrm{~s}^{-1},-2.3^{\circ} \mathrm{C}$ and $7.2 \mathrm{~m} \mathrm{~s}^{-1}$, respectively. The TSP concentrations in the samples ranged between 0.9 and $42.6 \mu \mathrm{g} \mathrm{m}^{-3}$ with a mean $9.3 \pm 9.2 \mu \mathrm{g} \mathrm{m}^{-3}$ (Fig. S2). Wind-rose diagrams are depicted in Fig. S3. The prevailing wind direction was the west-north $(\mathrm{W}-\mathrm{N}$, frequency: $>50 \%$ ) and east-southeast (E-SE, frequency: approximately 25\%). In the austral summer, the $\mathrm{W}-\mathrm{N}$ wind prevailed, while E-SE wind dominated in the austral winter. The backward 
trajectory indicated that King George Island was obviously affected by air masses coming from South America and adjacent ocean areas, especially in the austral summer (Fig. S4).

\section{2. $P C B$ concentrations and congener profile}

PCB concentrations (gas + particle) are summarized in Fig. 2A and Table S1. The sum concentrations ranged from 5.87 to $72.7 \mathrm{pg} \mathrm{m}^{-3}$, with an average of $26.1 \pm 13.1 \mathrm{pg} \mathrm{m}^{-3}$. The concentrations of 7 indicator PCBs (PCB-28, $-52,101,118,138,153$ and -180) were in the range of $0.91-35.9 \mathrm{pg} \mathrm{m}^{-3}$ with a mean value of $5.39 \mathrm{pg} \mathrm{m}^{-3}$, which was generally in line with our previous data based on PUF-disk PAS in the austral summer of 2009-2010 (1.66-6.50 $\mathrm{pg} \mathrm{m}^{-3}$ with an average of $4.34 \mathrm{pg} \mathrm{m}^{-3}$ ) (Li et al., 2012a), but slightly higher than the results in XAD resin PAS (0.70-1.64 $\mathrm{pg} \mathrm{m}^{-3}$ with a mean $1.14 \mathrm{pg} \mathrm{m}^{-3}$ ) (Li et al., 2012b). The present results were also in accordance with the previous studies in West Antarctica after the 2000's. To illustrate, the concentrations of 7 indicator PCBs ranged from $\sim 1$ to $4 \mathrm{pg} \mathrm{m}^{-3}$ in the Chilean station in 2010 using PUF-disk PAS (Pozo et al., 2014), and in the range of $0.85-3.12 \mathrm{pg} \mathrm{m}^{-3}$ in the Korean Antarctic Research Station in 2004-2005, based on XAD resin PAS (Choi et al., 2008). However, the present results were relatively lower than those reported earlier (Kallenborn et al., 1998; Montone et al., 2003). As summarized by Bengston Nash (2011), the atmospheric $\Sigma_{6}$ PCB (congeners
$28,52,101,138,153,180)$ concentrations ranged between 20 and $43 \mathrm{pg} \mathrm{m}^{-3}$ before the 2000's in the Antarctic Peninsula. Compared with other sites in Antarctica, our results were one order of magnitude higher than those from Terra Nova Bay, where the $\Sigma_{57} \mathrm{PCB}$ concentrations were in the range of $0.61-1.78 \mathrm{pg} \mathrm{m}^{-3}$ over the austral summer of 2003-2004 (Gambaro et al., 2005), and $\Sigma_{22}$ PCBs ranged $0.16-2.07 \mathrm{pg} \mathrm{m}^{-3}$ over the austral summer of 2009-2010 when using HVAS (Piazza et al., 2013). The present results were also higher than those from Norwegian Troll station in Dronning Maud Land, where the $\Sigma_{12} \mathrm{PCBs}$ concentrations ranged between 0.78 and $3.68 \mathrm{pg} \mathrm{m}^{-3}$ over $2007-2010$ based on HVAS (Kallenborn et al., 2013).

Among the PCB congeners, the non-Aroclor congener PCB-11 (3,3'-dichlorobiphenyl) was predominant with the concentration range of 4.84-61.9 $\mathrm{pg} \mathrm{m}^{-3}$ (mean $20.7 \mathrm{pg} \mathrm{m}^{-3}$ ), which accounted for $79 \%$ of $\Sigma_{20} \mathrm{PCBs}$ on average. This was consistent with our previous result (3.60-31.4 $\mathrm{pg} \mathrm{m}^{-3}$; Li et al., 2012a) and the observation in Korean Antarctic Research Station (mean $60 \mathrm{pg} \mathrm{m}^{-3}$; Choi et al., 2008). PCB-11 is not directly derived from commercial Aroclor and Clophen mixtures (Schulz et al., 1989). It has been found in an extremely high level in yellow pigment products (Shang et al., 2014), as well as in paint and pigment manufacturing as a byproduct (Hu et al., 2008). The extremely high level in air suggested that more attention should be paid to understanding its source in Antarctica. Apart from PCB-11, 7 indicator PCBs

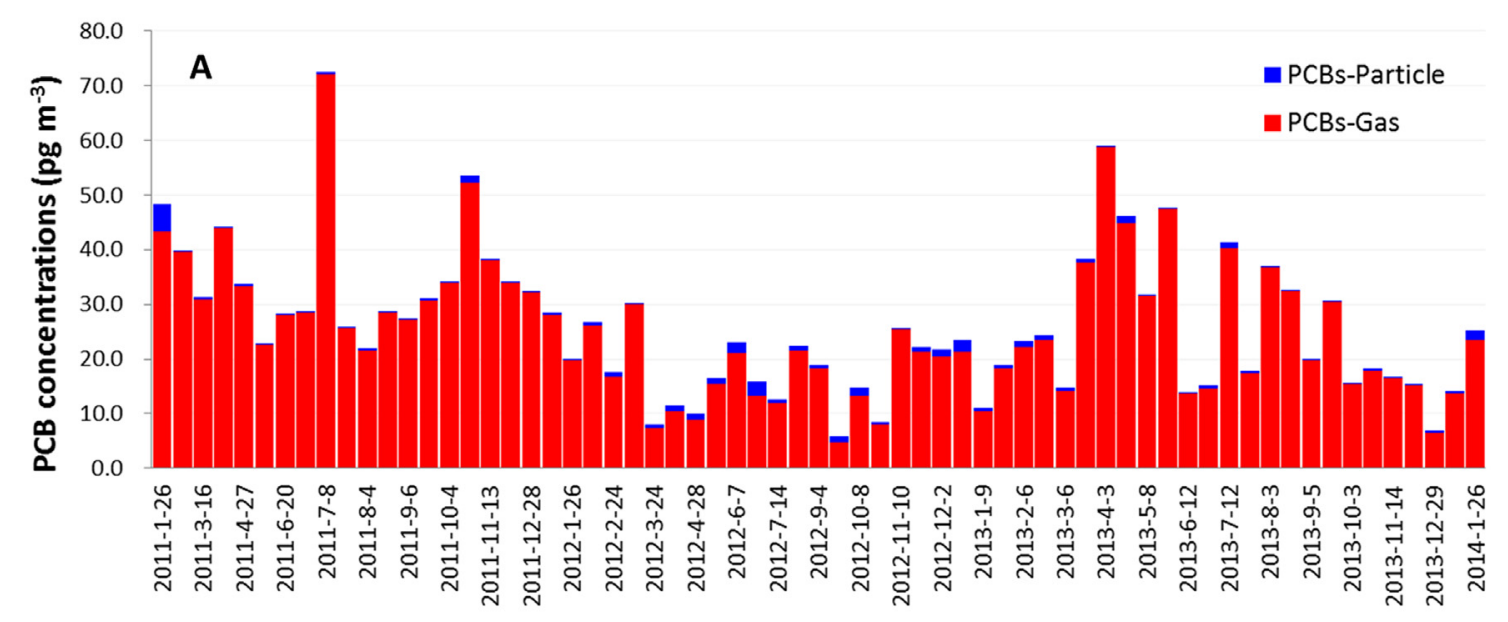

Sampling date

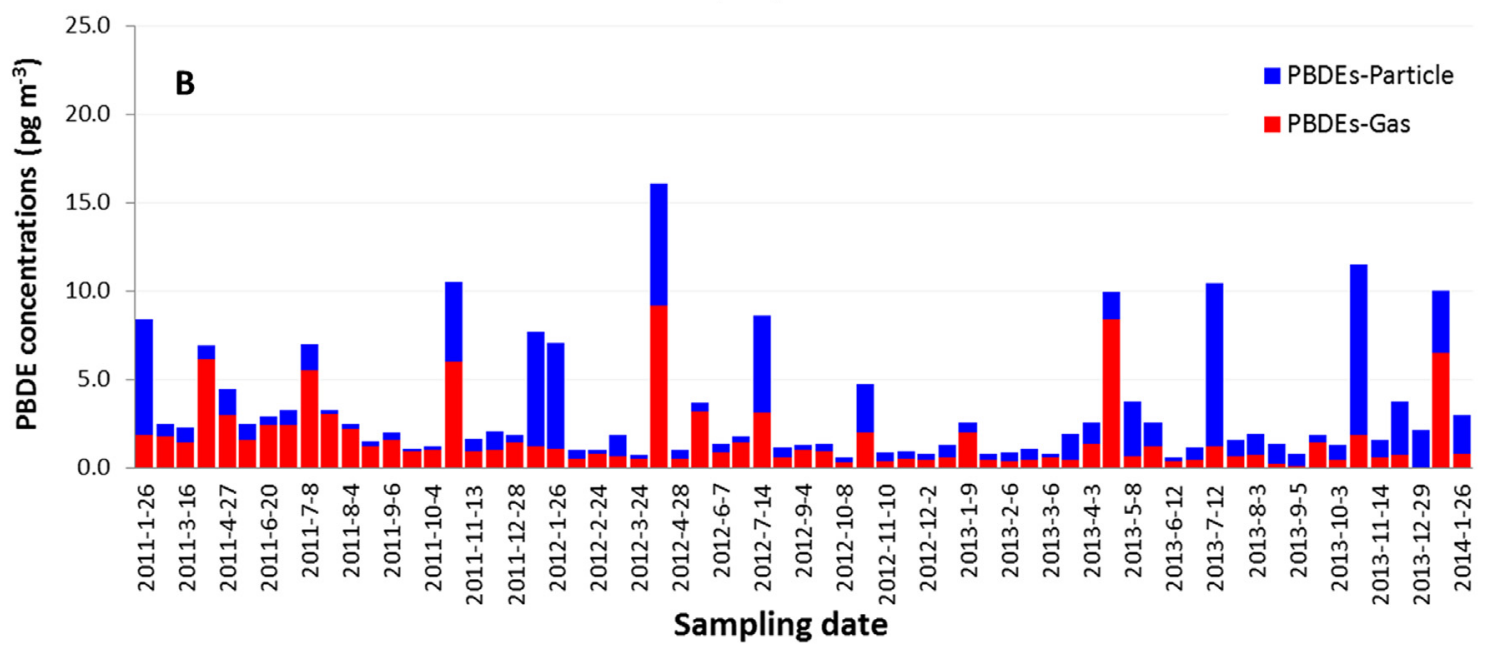

Fig. 2. The levels and distribution of PCBs (A) and PBDEs (B) in the Antarctic air over the entire sampling period. 
contributed to $20 \%$ of $\Sigma_{20}$ PCBs on average, of which PCB-28 and -52 were predominant with a mean value of 4.57 (85\% of indicator PCBs) and $0.46 \mathrm{pg} \mathrm{m}^{-3}$ ( $8 \%$ of indicator PCBs), respectively. This was also in agreement with the observation in our previous studies (Li et al., 2012a, 2012b).

\subsection{Chiral signature of $P C B S$}

Chiral compounds are commercially manufactured as racemates containing the identical proportions of two enantiomers $(\mathrm{EF}=0.5)$. The enantiomeric ratios are constant during physical (e.g., air-water exchange, sorption, volatilization, etc.) and chemical processes (e.g., abiotic reactions). However, biological and microbiological processes may be enantioselective and yield nonracemic residues in the environment (i.e. $\mathrm{EF} \neq 0.5$ ), where the chiral signature will differentiate from the primary source characters. Thus, chiral characteristic could be an important tool for tracking the transport pathway and fate of POPs in the environment (Bidleman et al., 2012). The present work is one of the very few studies that reported the chiral signature of PCBs in Antarctic air (Wang et al., 2015). As shown in Fig. 3 and Fig. S5, the EF values of five chiral PCBs (PCB-95, -136, -149, -174 and -176) were in the ranges of $0.438-0.541,0.425-0.654,0.422-0.606,0.193-0.830$ and $0.288-0.724$, respectively. Most EF values fell outside the $95 \%$ confidence intervals of the racemic standards, indicating a nonracemic residue of chiral PCBs in the west Antarctic air.

Among these chiral compounds, the mean EF values of PCB-95 $(0.496 \pm 0.017)$ and $-149(0.491 \pm 0.036)$ were close to 0.5 (Fig. S5), and there were no significant differences from the racemic values $(p>0.05)$. By contrast, the EFs of PCB-136 (0.518 \pm 0.038$)$ significantly deviated from the racemic values $(0.498 \pm 0.007$, $p<0.001$ ), indicating a stereoselective depletion of $(-)$ PCB-136 in the samples. Although the EFs of PCB-174 $(0.499 \pm 0.094)$ and -176 $(0.514 \pm 0.064)$ were not significantly different from the racemic values $(p>0.05)$, the wide variation of EFs indicated a stereoselective depletion of these chiral PCBs in air. This was generally consistent with our previous observation (Wang et al., 2015). The relationship between the chiral PCB concentrations and their EFs (or the deviation from racemic (DFR) which was defined as $\mid$ EF-0.5|) (Kania-Korwel and Lehmler, 2013) were also evaluated. There was an obvious dependence relationship between them and near racemic compositions were found in the samples associated with high concentrations (Fig. S6). This phenomenon was also reported previously in the equatorial Indian Ocean (Huang et al., 2013) and the Arctic areas (Bidleman et al., 2012). The reason was still unknown, even though it was suspected to be related to more fresh

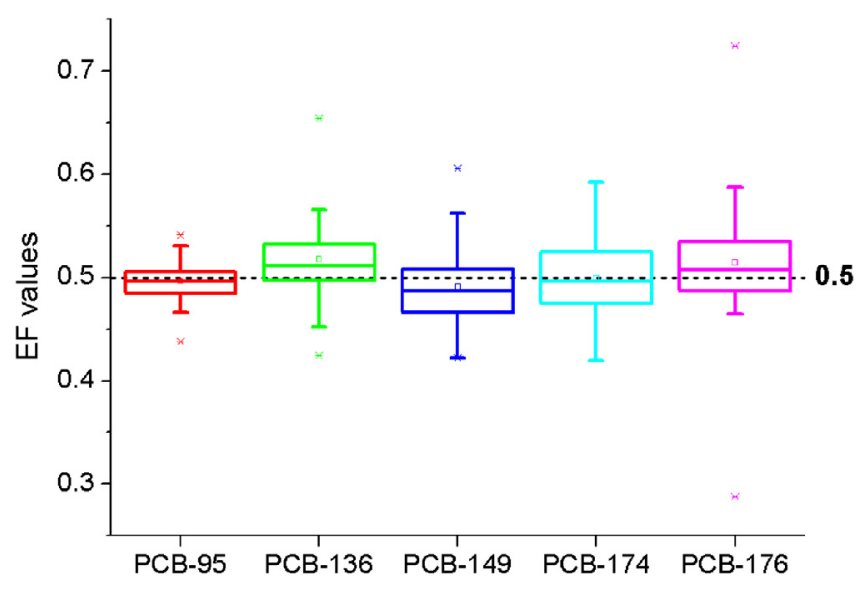

Fig. 3. The EF values of chiral PCBs in the Antarctic air samples. input of pollutants with higher concentrations (Huang et al., 2013).

The nonracemic residue of chiral PCBs may reflect the influence of secondary source on their atropisomer composition in air. As summarized by Bidleman et al. (2012), EFs in air over oceans, large lakes and seas varied from nearly racemic when long-range transport dominated to nonracemic upon volatilization from water. Considering that the present sampling area is much smaller than the surrounding ocean and most of the area is perennially covered by snow, seawater-air exchange may apparently affect the characteristics of chiral PCBs in air during LRAT into the west Antarctic environment.

\subsection{PBDE concentrations and congener profile}

The PBDE concentrations were in the range of $0.60-16.1 \mathrm{pg} \mathrm{m}^{-3}$, with a mean value of $3.28 \pm 3.31 \mathrm{pg} \mathrm{m}^{-3}$ (Fig. 2B, Table S2). This level was higher than the results based on PUF-disk PAS during the austral summer of 2009-2010 (Li et al., 2012a), where the concentrations of $\Sigma_{14}$ PBDEs ranged between 0.67 and $2.98 \mathrm{pg} \mathrm{m}^{-3}$ (average $1.52 \mathrm{pg} \mathrm{m}^{-3}$ ). The present results were relatively higher compared with the available data in Antarctic atmosphere, while slightly lower than those from the Arctic regions. The atmospheric concentrations of $\Sigma_{14}$ PBDEs were detected in the range of $0.14-1.69 \mathrm{pg} \mathrm{m}^{-3}$ in Terra Nova Bay, Antarctica over the austral summer of 2009-2010 using HVAS (Piazza et al., 2013). Möller et al. (2012) found a low value of $0.14 \mathrm{pg} \mathrm{m}^{-3}$ in airborne particle from a marine sampling site adjacent to East Antarctica in 2011. Su et al. (2007) reported that the concentrations of $\Sigma_{11}$ PBDEs ranged between 0.40 and $47 \mathrm{pg} \mathrm{m}^{-3}$ over the period of 2002-2004 at Alert, Nunavut, Canada, based on HVAS. The accumulated data from AMAP showed the concentrations of $\Sigma_{14}$ PBDEs ranged between 0.78 and $47 \mathrm{pg} \mathrm{m}^{-3}$ at Alertover over 2002-2005 and $0.14-3.3 \mathrm{pg} \mathrm{m}^{-3}$ at Nuuk (southwest Greenland) in 2005, respectively (Hung et al., 2010). In an expedition cruise from the Bohai Sea in China to the high Arctic, the average concentration of $\Sigma_{11}$ PBDEs in airborne particulates were found $17.3 \mathrm{pg} \mathrm{m}^{-3}$ in the Arctic (Wang et al., 2005). Based on XAD resin PAS, Shen et al. (2006) found $\sum_{5}$ PBDEs (BDE-47, -99, -100, -153, -154) in the range of $0.3-68 \mathrm{pg} \mathrm{m}^{-3}$ from the Canadian Arctic in 2000-2001.

Regarding the congener profiles, BDE-209 predominated in PBDEs with the concentration range of $0.18-6.35 \mathrm{pg} \mathrm{m}^{-3}$, which accounted for $41 \%$ of $\Sigma_{27}$ PBDEs on average. This was consistent with the observation by Dickhut et al. (2012), but different from our previous observation in which BDE-209 was not detected in the PUF-disk PAS (Li et al., 2012a). The discrepancy suggested underestimation of the level of high halogenated compounds, i.e. BDE209 in the PUF-disk PAS in this remote environment, although a higher sampling rate $\left(14 \mathrm{~m}^{3} \mathrm{day}^{-1}\right.$ ) was performed (Li et al., 2012a). This may be because BDE-209 is nearly completely particle-bound (Harner and Shoeib, 2002), while PAS mainly adsorbs the compounds in gas phase. Furthermore, the lower brominated compounds BDE-28, -17 and -47 contributed to $14 \%, 10 \%$ and $4 \%$ of $\Sigma_{27}$ PBDEs, respectively. In addition, some signature congeners in the technical formulations (i.e. Penta-, Octa- and Deca-BDE) have also been detected in a relatively low percentage $(<5 \%)$, such as BDE-99, -100, -153, -154, -183,-206 and -207. Due to limited volatility and LRAT potential, these higher brominated compounds may rely on local source around the sampling site. Previously, Hale et al. (2008) have found abundant BDE-209 in sludge and dust, as well as sediment near the McMurdo wastewater outfall, Antarctica. Wild et al. (2015) also found PBDEs including BDE-209 in indoor dust and treated wastewater effluent of Australian Antarctic research station (Casey Station), and the concentrations decreased when the distance from the station increased. These studies confirmed the research station as a source of PBDEs to the local 
environment. The assumption on the local source of Deca-PBDE can be demonstrated by the relationship between the concentrations of signature congeners deriving from the technical formulations (Table S3). Significant correlation was obtained between BDE-209 and BDE-206 or -207 ( $p \leq 0.001)$, while no such relationship was observed between BDE-209 and other congeners except BDE-183 ( $p=0.035$ ). In addition, the lighter congeners (IUPAC number $\leq 183$ ) showed significant correlations between each other $(p<0.001)$ except BDE-183 vs. BDE-100 ( $p>0.05)$, while the heavier congeners (IUPAC number $\geq 183$ ) were significantly correlated with each other $(p<0.05)$, indicating different sources between heavier and lighter PBDEs. The ratios of BDE-47/-99 and BDE-99/-100 can also provide insight into the source and fate of PBDEs. The degradation rates for BDE-47 and 100 were estimated to be higher than that for BDE-99 in air (Wania and Dugani, 2003). Therefore, ratios of BDE-47/99 were expected to decrease after long-range transport, while those of BDE-99/100 increased. In the present study, the mean ratio of BDE-47/-99 was $4.0 \pm 3.7$, higher than those in the penta-BDE formulations (approximately 1 in Bromkal 70-5DE and 0.8 in DE-71) (La Guardia et al., 2006). Meanwhile, the ratio of BDE-99/-100 was $5.7 \pm 3.1$, higher than that in DE-71 (3.7) but approaching to that in Bromkal 70-5DE (5.7) (La Guardia et al., 2006). Higher abundance of BDE-47 was also reported in the field environment due to the photolytic debromination of higher brominated BDEs, especially BDE-209 (Bezares-Cruz et al., 2004). This may explain the higher ratio of BDE-47/-99 in the air samples due to strong ultraviolet radiation in Antarctica. The relationship between the signature congeners thus confirmed occurrence of local source of PBDEs and photodegradation of higher brominated BDEs in the environment.

\subsection{Temporal trend of PCBs and PBDEs}

The atmospheric PCB concentrations generally showed no temporal tendency over the sampling period, although the level was slightly lower in 2012 compared with 2011 and 2013. However, as shown in Table S1 and Fig. S7, the level of 7 indicator PCBs declined over the three years, and the concentrations in 2012 and 2013 were approximately one order of magnitude lower than those in 2011. It was mainly due to the significant decline of the most abundant congeners (i.e. PCB-28 and -52) from 2011 to 2012 $(p<0.001)$. However, no evident temporal trends were observed for other congeners including PCB- 11 . This reduction was very rapid compared with the study in Arctic site with the elimination halflives of PCBs of $>4$ years (Hung et al., 2010). It may be due to more precipitation in 2012. The amount of precipitation increased by $50 \%$ in 2012, most of which was in the form of snowfall between April and October (Yang et al., 2013). The snowfall can efficiently scavenge the airborne POPs (Dickhut et al., 2012; Lei and Wania, 2004), resulting in a decline of atmospheric PCB levels in 2012. This can also explain the relatively lower level of PCB-11 in 2012. On the other hand, the annual mean wind speed in 2012 increased by $0.2 \mathrm{~m} \mathrm{~s}^{-1}$ compared to that in 2011, which facilitated transport of the particle-bound heavier POPs. Therefore, the heavier congeners had a generally constant level in the samples. This was supported by the increased particle-phase concentrations and the large variation of TSP concentrations in 2012 (Fig. 2A and Fig. S2).

For PBDEs, only a slight decline was observed for the gas-phase concentrations over the sampling period (2011: $2.41 \pm 1.68 \mathrm{pg} \mathrm{m}^{-3}$; 2012: $1.43 \pm 1.95 \mathrm{pg} \mathrm{m}^{-3} ; 2013: 1.04 \pm 1.71 \mathrm{pg} \mathrm{m}^{-3}$ ) (Fig. 2B), while no significance was obtained between the concentrations in the different years $(p>0.05)$. This tendency, similar to PCBs, was mainly attributed to reduction of the most abundant congeners in gas phase (i.e. BDE-17, -28 and -47). However, BDE-209 was generally at a constant level during the entire sampling period
(Table S2, Fig. S8). No significant correlation was observed between neither the gas-phase nor the particle bound BDE-209 and TSP concentrations $(p>0.05)$. Despite that, evidently higher particlephase PBDE concentrations were measured in 2012 (Fig. 2B), consistent with the observation for PCBs.

\subsection{Seasonal variation and temperature dependence}

The levels of PCB-28 and -52 presented an evidential seasonal variation with relatively low concentrations in the austral winter in 2011 and 2012, while no obvious variations were found for other PCBs (excluding PCB-11) over the entire sampling period. By contrast, PCB-11 had slightly higher levels in the austral winter in 2011 and 2013 (Fig. S7), suggesting the different source of PCB-11 from the PCB congeners deriving from commercial products (i.e. Aroclor and Clophen mixtures).

Unlike lighter PCBs, no seasonal variation was observed for individual PBDEs in the samples. The absence of seasonal variation for lighter PBDEs was inconsistent with the observations in the Canadian High Arctic (Alert, Nunavut) (Hung et al., 2010, 2016; Su et al., 2007), Su et al. (2007) attributed the lack of seasonal variation of heavier PBDEs to a combination of their elevated input during the Arctic haze season, ability to bind to particles and higher tendency to deposit in the polar atmosphere.

Ambient temperature was considered important to control seasonality of semi-volatile organic compounds (SVOCs) in air due to its marked effect on the chemical partitioning between air and surface media (e.g., soil and water). The logarithms of gaseous concentrations were generally regressed well with reciprocal temperature $(1 / T)$ with a slope $m$ (Wania et al., 1998). A shallow slope $m$, namely, low temperature dependence, indicated that longrange transport controlled atmospheric levels in the sampling site, while a steep slope indicated volatilization emission from surface in the vicinity of the site (Wania et al., 1998). We tested the relationship of the logarithm of gaseous concentrations of PCBs and PBDEs against $1 / T$, and the results are given in Table S4. Lighter PCBs (i.e., PCB-28, -52 and -101) showed significant temperature dependence in 2011 and 2012 ( $p<0.05$ ), while no such relationships were found for other congeners (including PCBs and PBDEs) $(p>0.05)$. The temperature dependence of lighter PCBs with steep slopes ( $m \leq-1704$ ) suggested the influence of volatilization emission from local surface to the air concentrations (Wania et al., 1998). The phenomenon has also been observed in Livingston Island (Antarctica) (Cabrerizo et al., 2013) and Arctic areas (Ma et al., 2011; Zhao et al., 2015), where temperature-driven air-surface exchange became an important factor to control POPs levels in polar air. This was also supported by the present observation in 2013. Due to increased precipitation by 50\% in 2012 (Yang et al., 2013), the island was mostly covered by snow in the subsequent austral summer. Thus, the dampened air-surface (i.e. soil) exchange may result in disappeared temperature dependence of lighter PCBs in 2013. On the other hand, the higher levels in the austral summer can also be caused by enhanced advection of air masses carrying pollutants from the source areas. The backward trajectories indicated that the sampling site was obviously affected by the emissions in South America (Fig. S4). Previous studies have reported high levels of airborne PCBs in South America and southeast Atlantic Ocean with elevated levels of PCBs in the austral summer (Ware, 2006; McConnell et al., 2013). In the present study, the air concentrations of lighter PCBs (including PCB-28, -25 and -101) were significantly higher when air mass passed by South America and adjacent ocean areas $(p<0.05)$, suggesting LRAT an additional pathway of lighter PCBs to West Antarctica. This assumption was supported by variation of the slope $m$. As reported previously by Wania et al. (1998) and Breivik et al. (2004), the less volatile PCBs 
generally showed a stronger temperature dependence, yielding a steeper slope $m$. However, reversed situation was obtained in the present study, which suggested more input of the lighter congeners into the ambient air. This provided a good confirmation that LRAT is an important pathway for lighter PCBs into the Antarctic environment because of their higher transport potential.

The slopes of $\ln$ (PCB-28, -52 and -101) versus $1 / T$ were steeper in 2012 compared with those in 2011, which implied elevated volatilization from local and/or regional surfaces in 2012 (Wania et al., 1998). In fact, the elevated annual air temperature and wind speeds possibly increased air-surface exchange of lighter PCBs (Wania et al., 1998; Breivik et al., 2004). However, as mentioned above, the precipitation markedly increased in 2012, especially the snowfall between April and October (Yang et al., 2013). This may efficiently reduce POPs levels in air in the austral winter (Lei and Wania, 2004), thus, contributing to the steeper slopes of $\ln$ (PCB-28, -52 and -101) versus 1/T in 2012.

Regarding the absence of temperature dependence of PBDEs and heavier PCBs, the shallow slopes suggested the influence of long-range advection of these pollutants on the sampling area (Wania et al., 1998). This could be supported by the observation on the aerosol-mediated transport of PBDEs (BDE-47, -99, and -100) in air, snow and sea ice to West Antarctica between 2001 and 2007 (Dickhut et al., 2012). The lack of temperature dependence of PCBs was attributed to the fact that a temperature threshold for re- evaporation was not reached in the low temperature (Oehme et al., 1996). This explanation may also be valid for our study since only lighter PCBs exhibited temperature dependence. On the other hand, constantly high levels of BDE-209 were measured, especially in the austral winter when the E-SE wind (originated from Antarctica) dominated (Fig. S3). This also provided evidence for occurrence of local and/or regional source of Deca-PBDE, in agreement with the implication from the relationships between the signature congeners in air mentioned previously. In contrast to BDE-209 and heavier PCBs, PCB-11 has a higher volatility and can undergo LRAT easily. The constant high level and lack of temperature dependence suggested LRAT an important pathway for PCB-11 to West Antarctica.

\subsection{Gas/particle partitioning of PCBs and PBDEs}

The $\sum{ }_{20} \mathrm{PCBs}$ were found exclusively in gas phase (mean $97 \%$ ), while the $\sum 27 \mathrm{PBDEs}$ in gas phase were comparable to the particle phase (mean $49 \%$ vs. 51\%). As illustrated in Fig. 4, the lower halogenated congeners tended to distribute in the gas phase, while the higher halogenated congeners were more associated in the particle phase.

The gas/particle $(\mathrm{G} / \mathrm{P})$ partitioning of SVOCs was considered a very important process that primarily governed their atmospheric fate (Lohmann et al., 2000). $K_{P}$ was commonly used to describe the
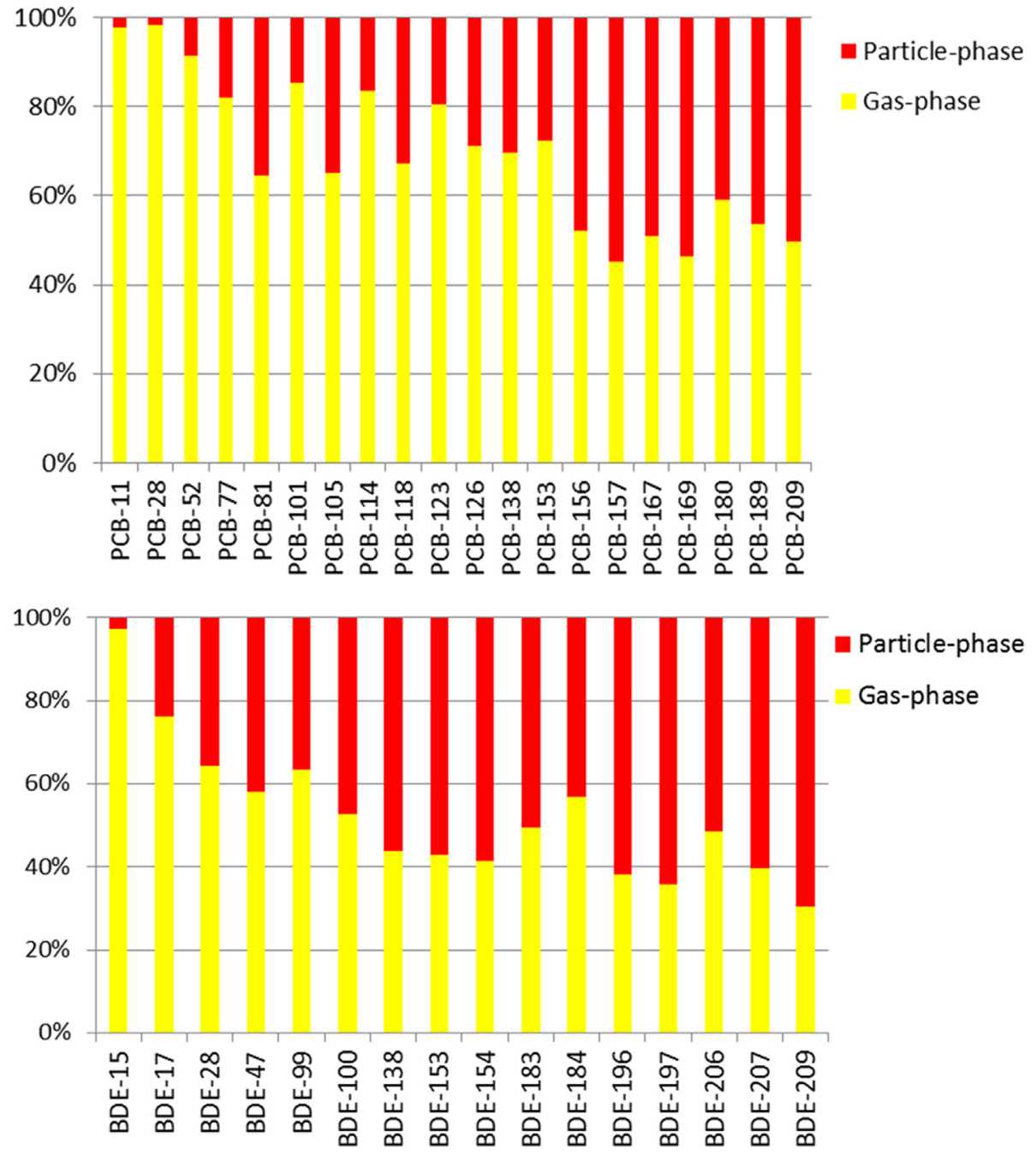

Fig. 4. The relative gas/particle distributions of individual PCBs and PBDEs in the air samples. 
G/P partitioning behavior of SVOCs. It has been shown that a linear relationship between $\log K_{P}$ and $\log K_{O A}$ ( $K_{O A}$, octanol-air partition coefficient) (Harner and Bidleman, 1998; Li and Jia, 2014) or $\log P_{L}$ ( $P_{L}$ is sub-cooled liquid vapor pressure) ( $\mathrm{Li}$ and Jia, 2014; Pankow and Bidleman, 1992). Under the equilibrium conditions, log $K_{P}$ was linearly regressed against $\log K_{O A}$ using an equilibrium-statebased equation (log $K_{P E}$ ) (Harner and Bidleman, 1998). Recently, Li and Jia (2014) developed a steady-state model to predict the $\mathrm{G} / \mathrm{P}$ partitioning behavior of PBDEs in air, and the empirical predicted $\log K_{P P}$ was expressed as a function of $\log K_{O A}$. Li et al. (2015) further developed a theoretical equation $\left(\log K_{P S}\right)$, which was considered superior to the equilibrium-state-based equation and successfully applied in some cases. The further details about these two equations are given in SM. In order to evaluate the G/P partitioning behaviors of PCBs and PBDEs in the Antarctic air, both the equilibrium-state-based equation and steady-state-based equation were used to explore the relationship between $\log K_{P}$ and $\log K_{O A}$ (Fig. 5). It was obvious that the prediction data $\left(\log K_{P P}\right)$ generally well matched with the regression data $\left(\log K_{P R}\right)$, but not for the $\log$ $K_{P E}$ data. The slopes $(m)$ for $\log K_{P P}$ and $\log K_{P R}$ were 0.2357 and 0.326 , respectively, less than 1 , indicating that the gas/particle partitioning of PCBs and PBDEs deviated largely from the equilibrium state. This phenomenon was consistent with the results on PBDEs in the north temperate zone air (Li and Jia, 2014). Compared with the equilibrium state model $\left(\log K_{P E}\right)$, the curve of $\log K_{P S}$ was closer to the regression line of $\log K_{P R}$, especially for heavy congeners with relatively larger $\log K_{O A}$ values, e.g., PBDEs. Since the smaller $K_{O A}$ values were mainly associated with $P C B$ congeners, the relationships of $\log K_{P}$ against $\log K_{O A}$ were depicted separately for PCBs and PBDEs. As exhibited in Fig. S9, the $\log K_{P}$ data showed a significant correlation with $\log K_{O A}$ for PBDE congeners with $R^{2}$ of 0.1195 and $p<0.001$ (F-test). The regression line $\left(\log K_{P R}\right)$ matched well with the prediction data $\left(\log K_{P P}\right)$ and the curve of $\log K_{P S}$, but not the line of $\log K_{P E}$. This suggested that the steady-state-based equation could be applied to describe the gas/particle partitioning of PBDEs in the Antarctic air. For PCBs (Fig. S10), the log $K_{P}$ values were significantly correlated with $\log K_{O A}\left(R^{2}=0.337\right.$, $p<0.001)$ as well. The regression line of $\log K_{P R}$ generally matched the predicated result $\left(\log K_{P P}\right)$ well for the congeners with lower log $K_{O A}$ (less than about 11 ), but showed a large deviation from the log $K_{P E}$ data. This may indicate a non-equilibrium status of gas/particle partitioning of PCBs. However, this phenomenon could be well demonstrated using the empirical equation $\left(\log K_{P P}\right)$ developed for PBDEs in the north temperate zone air (Li and Jia, 2014). Moreover, since a large deviation between the regression line $\left(\log K_{P R}\right)$ and the predication line $\left(\log K_{P P}\right)$ could still be observed for the congeners with $\log K_{O A}>11$, the slope $m$ and intercept $b$ (Eqs. (5) and (6) in $\mathrm{SM}$ ) for linear regression may require a specified calculation for PCBs. As to $\log K_{P S}$, the curve deviated evidently from the regression line $\left(\log K_{P R}\right)$ and the predication line $\left(\log K_{P P}\right)$ for those congeners with lower $\log K_{O A}$. This phenomenon could also be found in the studies on PCBs in rural areas (Lohmann et al., 2000) and PBDEs in Guangzhou, Kunming Lhasa and Shanghai cities (Li and Jia, 2014). It was argued that newly released particles at the rural sites caused nonequilibrium partitioning at those sites for PCBs (Lohmann et al., 2000). The non-equilibrium term $(\log \alpha)$ could not be a positive number (see the physical meaning of $\alpha$ in Li et al. (2015)), thus, the $\log K_{P S}$ values would not be higher than the $\log K_{P E}$ values at the same $\log K_{O A}$. That is, the steady-state-based equation cannot perform well for lighter PCBs. Considering a relatively good match between the regression line $\left(\log K_{P R}\right)$ and predication line $\left(\log K_{P P}\right)$ for both PCBs and PBDEs, an additional term associating with environmental parameters (e.g., temperature, precipitation, humidity, wind speed, etc.) may be required in the steady-state-based equation to improve its performance in polar regions especially Antarctica.

It was noteworthy that a parameter $C=10$ was assumed during calculation, which was higher than the default value used in the study by Li et al. (2015). A higher value of $C$ was recommended when high wind speed occurred, such as $C=50$ was assumed at Waliguan where the annual average wind speed reached $4.6 \mathrm{~m} \mathrm{~s}^{-1}$ (Li et al., 2015). In Great Wall Station the annual average wind speed

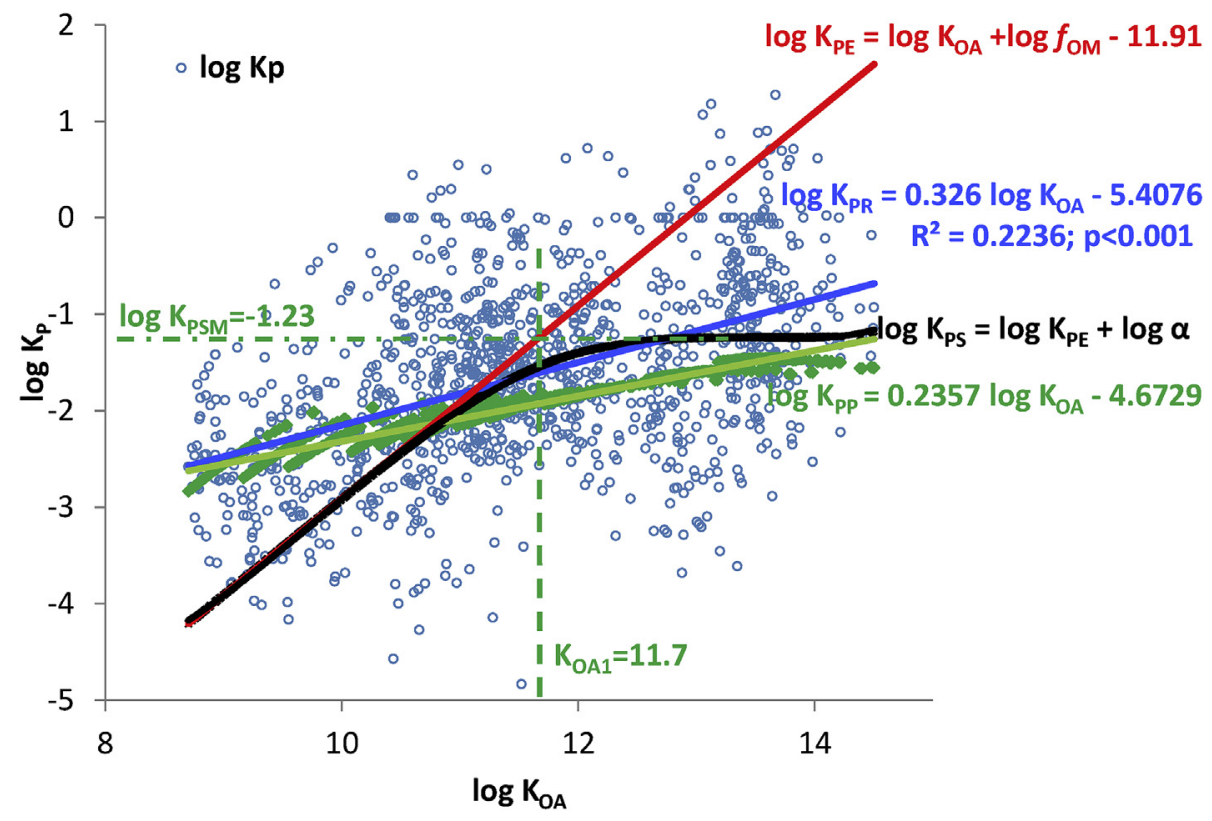

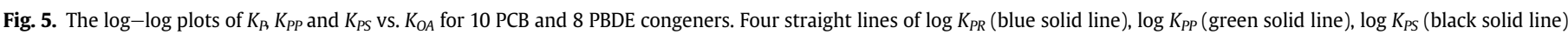

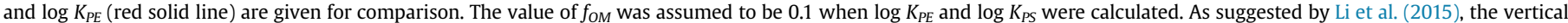

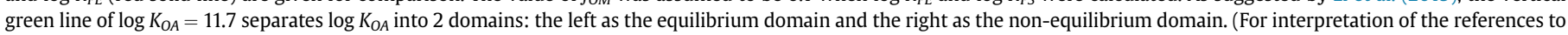
colour in this figure legend, the reader is referred to the web version of this article.) 
was higher than $7 \mathrm{~m} \mathrm{~s}^{-1}$, a higher value of $C$ should be used in the steady-state-based equation. However, the values higher than 10 led to larger deviations between $\log K_{P S}$ and $\log K_{P P}$ or $\log K_{P R}$ when $\log K_{O A}>\log K_{O A 1}\left(\log K_{O A 1}\right.$, a threshold value divided the whole range of $\log K_{O A}$ into equilibrium and non-equilibrium domains. Fig. 5 and Fig. S11). $C$ was a parameter introduced in the term of the chemical's molecular diffusivity for the particle film in air (Eq. (10) in SM). Higher temperature apparently benefited the chemical's molecular diffusion during gas/particle exchange (Schwarzenbach et al., 1993). According to Li and Jia (2014), the annual mean temperature was $17.7^{\circ} \mathrm{C}$ (range $3.3-27.8^{\circ} \mathrm{C}$ ) in Waliguan, which was much higher than that in the present study area. Therefore, in despite of stronger wind in the Antarctic area (annual value $>7 \mathrm{~m} \mathrm{~s}^{-1}$ ), a lower temperature may reduce the variation of the chemical's molecular diffusivity during gas/particle exchange. In this case, a value of 10 was properly assumed in the steady-statebased model. This suggested evident correlation between the parameter $C$ and air temperature besides wind speed.

\section{Conclusions}

Extremely low levels of PCBs and PBDEs were measured in the west Antarctic air over the three-year sampling period (Jan 2011-2014). Lighter PCBs and PBDEs showed a decline tendency from 2011 to 2012, which may be mainly caused by variation of the meteorological condition. Longer-term monitoring data are required before significant trends can be identified.

The source and fate of PCBs and PBDEs were well demonstrated via the seasonal variation, temperature dependence and chiral characteristics in this remote environment. The results suggested that revolatilization emission from surfaces in a local and/or regional scale could be an important factor for lighter PCBs (excluding PCB-11) in the west Antarctic air, while LRAT acted as a main pathway for both PCBs and PBDEs to the sampling area. The chiral signature indicated nonracemic residues of five chiral PCBs in air, which also provided evidence for occurrence of LRAT and airsurface (seawater) exchange of POPs during transport. Furthermore, local source of Deca-BDE and photodegradation of higher brominated BDEs were reflected by the correlations and ratios between the air concentrations of different signature congeners deriving from the technical formulations. Despite that, further study is warranted to confirm the source of Deca-BDE in King George Island, West Antarctica. It is notable that significantly high level of PCB-11 was constantly observed in air over the sampling period. LRAT is suggested as an important pathway to the West Antarctica. However, local sources from research stations might also be possible since PCB-11 is believed to be derived from various pigment products. The extent of the contribution from the research stations to the local PCB-11 levels in air requires further study.

The G/P partitioning behaviors of POPs were evaluated by the traditional equilibrium-state-based equation and newly developed steady-state-based equation. Using the specified parameters in the equations, the steady-state-based model showed a better performance than the equilibrium-state-based equation, especially for those compounds with larger $\log K_{O A}(>11)$, of which the G/P partitioning reached non-equilibrium status. Nevertheless, the steadystate-based equation still underestimated the partitioning of most PCBs $\left(\log K_{O A}<11\right)$ in the particle phase. That is, the steady-statebased equation should be specifically optimized when using it to describe the partitioning behaviors of those compounds with lower $\log K_{O A}$.

\section{Acknowledgments}

This study was jointly supported by National Natural Science
Foundation of China (41276195, 21477155 and 41676183), Chinese Academy of Sciences (XDB14010100 and YSW2013B01), the National Basic Research Program of China (2015CB453101) and the State Oceanic Administration, P.R. China (13/14GW05). The paper has benefited greatly from comments by three unknown referees. We greatly thank Drs. Thanh Wang and Dawei Geng from MTM Research Center, Örebro University for revising this manuscript. We also thank Chinese Arctic and Antarctic Ministration for the arrangement during Chinese Antarctic Expedition.

\section{Appendix A. Supplementary data}

Supplementary data related to this article can be found at http:// dx.doi.org/10.1016/j.atmosenv.2016.11.036.

\section{References}

Baek, S.Y., Choi, S.D., Chang, Y.S., 2011. Three-year atmospheric monitoring of organochlorine pesticides and polychlorinated biphenyls in Polar Regions and the South Pacific. Environ. Sci. Technol. 45, 4475-4482.

Bengston Nash, S., 2011. Persistent organic pollutants in Antarctica: current and future research priorities. J. Environ. Monit. 13 (3), 497-504.

Bezares-Cruz, J., Jafvert, C.T., Hua, I., 2004. Solar photodecomposition of decabromodiphenyl ether: products and quantum yield. Environ. Sci. Technol. 38, 4149-4156.

Bidleman, T.F., Jantunen, L.M., Kurt-Karakus, P.B., Wong, F., 2012. Chiral persistent organic pollutants as tracers of atmospheric sources and fate: review and prospects for investigating climate change influences. Atmos. Pollut. Res. 3, $371-382$.

Breivik, K., Alcock, R., Li, Y.F., Bailey, R.E., Fiedler, H., Pacyna, J.M., 2004. Primary sources of selected POPs: regional and global scale emission inventories. Environ. Pollut. 128 (1-2), 3-16.

Cabrerizo, A., Dachs, J., Barceló, D., Jones, K.C., 2013. Climatic and biogeochemical controls on the remobilization and reservoirs of persistent organic pollutants in Antarctica. Environ. Sci. Technol. 47 (9), 4299-4306.

Choi, S.D., Baek, S.Y., Chang, Y.S., Wania, F., Ikonomou, M.G., Yoon, Y.J., Park, B.K., Hong, S., 2008. Passive air sampling of polychlorinated biphenyls and organochlorine pesticides at the Korean arctic and Antarctic research stations: implications for long-range transport and local pollution. Environ. Sci. Technol. 42, 7125-7131.

Dickhut, R.M., Cincinelli, A., Cochran, M., Kylin, H., 2012. Aerosol-mediated transport and deposition of brominated diphenyl ethers to Antarctica. Environ. Sci. Technol. 46 (6), 3135-3140.

Gambaro, A., Manodori, L., Zangrando, R., Cincinelli, A., Capodaglio, G., Cescon, P., 2005. Atmospheric PCB concentrations at Terra Nova Bay, Antarctica. Environ. Sci. Technol. 39, 9406-9411.

Genualdi, S.A., Simonich, S.L.M., Primbs, T.K., Bidleman, T.F., Jantunen, L.M., Ryoo, K.S., Zhu, T., 2009. Enantiomeric signatures of organochlorine pesticides in Asian, trans-Pacific, and Western U.S. air masses. Environ. Sci. Technol. 43, 2806-2811.

Hale, R.C., Kim, S.L., Harvey, E., La Guardia, M.J., Mainor, T.M., Bush, E.O., Jacobs, E.M., 2008. Antarctic research bases: local sources of polybrominated diphenlyl ether (PBDE) flame retardants, Environ. Sci. Technol, 42, 1452-1457.

Harner, T., Bidleman, T.F., 1998. Octanol-air partition coefficient for describing particle/gas partitioning of aromatic compounds in urban air. Environ. Sci. Technol. 32 (10), 1494-1502.

Harner, T., Shoeib, M., 2002. Measurements of octanol-air partition coefficients $\left(\mathrm{K}_{\mathrm{OA}}\right)$ for polybrominated diphenyl ethers (PBDEs): predicting partitioning in the environment. J. Chem. Eng. Data 47 (2), 228-232.

Hu, D.F., Martinen, A., Hornbuckle, K.C., 2008. Discovery of non-aroclor PCB (3,3'dichlorobiphenyl) in Chicago air. Environ. Sci. Technol. 42, 7873-7877.

Huang, Y., Xu, Y., Li, J., Xu, W., Zhang, G., Cheng, Z., Liu, J., Wang, Y., Tian, C., 2013. Organochlorine pesticides in the atmosphere and surface water from the equatorial Indian ocean: enantiomeric signatures, sources, and fate. Environ. Sci. Technol. 47, 13395-13403.

Hung, H., Kallenborn, R., Breivik, K., Su, Y., Brorström-Lundén, E., Olafsdottir, K., Thorlacius, J.M., Leppänen, S., Bossi, R., Skov, H., Manø, S., Patton, G.W., Stern, G., Sverko, E., Fellin, P., 2010. Atmospheric monitoring of organic pollutants in the arctic under the arctic monitoring and Assessment Programme (AMAP): 19932006. Sci. Total Environ. 408 (15), 2854-2873.

Hung, H., Katsoyiannis, A.A., Brorström-Lundén, E., Olafsdottir, K., Aas, W., Breivik, K., Bohlin-Nizzetto, P., Sigurdsson, A., Hakola, H., Bossi, R., Skov, H., Sverko, E., Barresi, E., Fellin, P., Wilson, S., 2016. Temporal trends of persistent organic pollutants (POPs) in arctic air: 20 years of monitoring under the arctic monitoring and Assessment Programme (AMAP). Environ. Pollut. http:// dx.doi.org/10.1016/j.envpol.2016.01.079.

Kallenborn, R., Oehme, M., Wynn-Williams, D.D., Schlabach, M., Harris, J., 1998. Ambient air levels and atmospheric long-range transport of persistent organochlorines to Signy Island, Antarctica. Sci. Total Environ. 220, 167-180.

Kallenborn, R., Breivik, K., Eckhardt, S., Lunder, C.R., Manø, S., Schlabach, M., 
Stohl, A., 2013. Long-term monitoring of persistent organic pollutants (POPs) at the Norwegian Troll station in Dronning Maud Land, Antarctica. Atmos. Chem. Phys. 13, 6983-6992.

Kania-Korwel, I., Lehmler, H.J., 2013. Assigning atropisomer elution orders using atropisomerically enriched polychlorinated biphenyl fractions generated by microsomal metabolism. J. Chromatogr. A 1278, 133-144.

Kong, D., MacLeod, M., Hung, H., Cousins, I.T., 2014. Statistical analysis of long-term monitoring data for persistent organic pollutants in the atmosphere at 20 monitoring stations broadly indicates declining concentrations. Environ. Sci. Technol. 48 (21), 12492-12499.

Kurt-Karakus, P.B., Bidleman, T.F., Jones, K.C., 2005. Chiral organochlorine pesticide signatures in global background soils. Environ. Sci. Technol. 39 (22), 8671-8677.

La Guardia, M.J., Hale, R.C., Harveym, E., 2006. Detailed polybrominated diphenyl ether (PBDE) congener composition of the widely used penta-, octa-, and decaPBDE technical flame-retardant mixtures. Environ. Sci. Technol. 40, 6247-6254.

Lei, Y.D., Wania, F., 2004. Is rain or snow a more efficient scavenger of organic chemicals? Atmos. Environ. 38 (22), 3557-3571.

Li, Y., Geng, D., Liu, F., Wang, T., Wang, P., Zhang, Q., Jiang, G., 2012a. Study of PCBs and PBDEs in King George Island, Antarctica, using PUF passive air sampling. Atmos. Environ. 51, 140-145.

Li, Y., Geng, D., Hu, Y., Wang, P., Zhang, Q., Jiang, G., 2012b. Levels and distribution of polychlorinated biphenyls in the atmosphere close to Chinese Great Wall Station, Antarctica: results from XAD-resin passive air sampling. Chin. Sci. Bull. 57, 1499-1503.

Li, Y.F., Jia, H.L., 2014. Prediction of gas/particle partition quotients of polybrominated diphenyl ethers (PBDEs) in north temperate zone air: an empirical approach. Ecotoxicol. Environ. Saf. 108, 65-71.

Li, Y.F., Ma, W.L., Yang, M., 2015. Prediction of gas/particle partitioning of polybrominated diphenyl ethers (PBDEs) in global air: a theoretical study. Atmos. Chem. Phys. 15 (4), 1669-1681.

Lohmann, R., Harner, T., Thomas, G.O., Jones, K.C., 2000. A comparative study of the gas-particle partitioning of PCDD/Fs, PCBs, and PAHs. Environ. Sci. Technol. 34 (23), 4943-4951.

Ma, J., Hung, H., Tian, C., Kallenborn, R., 2011. Revolatilization of persistent organic pollutants in the Arctic induced by climate change. Nat. Clim. Change. 1 (1), 255-260.

McConnell, L., et al., 2013. Assessment of Persistent Organic Pollutants in the Atmosphere of Latin America. In Occurrence, Fate and Impact of Atmospheric Pollutants on Environmental and Human Health. ACS Symposium Series; American Chemical Society, Washington, DC, pp. 183-199.

Möller, A., Xie, Z., Cai, M., Sturm, R. Ebinghaus, R., 2012. Brominated flame retardants and Dechlorane Plus in the marine atmosphere from southeast Asia toward Antarctica. Environ. Sci. Technol. 46 (6), 3141-3148.

Montone, R.C., Taniguchi, S., Weber, R.R., 2003. PCBs in the atmosphere of king George island, Antarctica. Sci. Total Environ. 308, 167-173.

Muir, D.C.G., de Wit, C.A., 2010. Trends of legacy and new persistent organic pollutants in the circumpolar arctic: overview, conclusions, and recommendation. Sci. Total Environ. 408, 3044-3051.

Nizzetto, L., Lohmann, R., Gioia, R., Dachs, J., Jones, K.C., 2010. Atlantic Ocean surface waters buffer declining atmospheric concentrations of persistent organic pollutants. Environ. Sci. Technol. 44, 6978-6984.

Oehme, M., Haugen, J.E., Schlabach, M., 1996. Seasonal changes and relations between levels of organochlorines in arctic air: first year results of an all yearround monitoring program at Ny-Alesund, Svalbard, Norway. Environ. Sci. Technol. 30, 2294-2304.

Pankow, J.F., Bidleman, T.F., 1992. Interdependence of the slopes and intercepts from log-log correlations of measured gas-particle partitioning and vapor pressure I. Theory and analysis of available data. Atmos. Environ. 26A, 1071-1080.

Piazza, R., Gambaro, A., Argiriadis, E., Vecchiato, M., Zambon, S., Cescon, P. Barbante, C., 2013. Development of a method for simultaneous analysis of PCDDs, PCDFs, PCBs, PBDEs, PCNs and PAHs in Antarctic air. Anal. Bioanal. Chem. 405 (2-3), 917-932.

Pozo, K., Corsolini, S., Cincinelli, A., Martellini, T., Harner, T., Kukučka, P., Klánová, J. Barra, R., Mulder, M.D., Lammel, G., 2014. Persistent organic pollutants in the atmosphere of two Antarctic zones (Antarctic peninsula and ross sea) using passive air samplers (PUF disks). Organohalogen Compd. 76, 1047-1050.

Schulz, D.E., Petrick, G., Duinker, J.C., 1989. Complete characterization of polychlorinated biphenyl congeners in commercial aroclor and clophen mixtures by multidimensional gas-chromatography electron-capture detection. Environ. Sci. Technol. 23, 852-859.

Schwarzenbach, R.P., Gschwend, P.M., Imboden, D.M., 1993. Environmental Organic Chemistry. John Wiley\&Sons Inc., New York.

Shang, H., Li, Y., Wang, T., Wang, P., Zhang, H., Zhang, Q., Jiang, G., 2014. The presence of polychlorinated biphenyls in yellow pigment products in China with emphasis on 3,3'-dichlorobiphenyl (PCB 11). Chemosphere 98, 44-50.

Shen, L., Wania, F. Lei, Y.D., Teixeira, C., Muir, D.C.G., Xiao, H., 2006. Polychlorinated biphenyls and polybrominated diphenyl ethers in the North American atmosphere. Environ. Pollut. 144, 434-444.

Sladen, W.J.L., Menzie, C.M., Reichel, W.L., 1966. DDT residues in Adelie penguins and a Crabeater seal from Antarctica. Nature 210, 670-673.

Su, Y., Hung, H., Sverko, E., Fellin, P., Li, H., 2007. Multi-year measurements of polybrominated diphenyl ethers (PBDEs) in the Arctic atmosphere. Atmos. Environ, 41, 8725-8735.

Wang, X.M., Ding, X., Mai, B.X., Xie, Z.Q., Xiang, C.H., Sun, L.G., Sheng, G.Y., Fu, J.M., Zeng, E.Y., 2005. Polybrominated diphenyl ethers in airborne particulates collected during a research expedition from the Bohai Sea to the Arctic. Environ. Sci. Technol. 39, 7803-7809.

Wang, P., Zhang, Q., Li, Y., Zhu, C., Chen, Z., Zheng, S., Sun, H., Liang, Y., Jiang, G., 2015 Occurrence of chiral organochlorine compounds in the environmental matrices from King George Island and Ardley Island, west Antarctica. Sci. Rep. 5, 13913.

Wania, F., Haugen, J., Lei, Y., Mackay, D., 1998. Temperature dependence of atmospheric concentrations of semivolatile organic compounds. Environ. Sci. Technol. 32 (8), 1013-1021.

Wania, F., Dugani, C.B., 2003. Assessing the long-range transport potential of polybrominated diphenyl ethers: a comparison of four multimedia models. Environ. Toxicol. Chem. 22, 1252-1261.

Reviews of Environmental Contamination and Toxicology. In: Ware, G.W. (Ed.) 2006, vol. 185. Springer Press, New York.

Wild, S., McLagan, D., Schlabach, M., Bossi, R., Hawker, D., Cropp, R., King, C.K. Stark, J.S., Mondon, J., Bengston Nash, S., 2015. An Antarctic research station as a source of brominated and perfluorinated persistent organic pollutants to the local environment. Environ. Sci. Technol. 49 (1), 103-112.

Yang, Q., Zhang, B., Li, M., Meng, S., 2013. Analysis of weather and sea ice at the Antarctic Great Wall station in 2012. Adv. Polar Sci. 25 (3), 268-277.

Zhang, Q., Chen, Z., Li, Y., Wang, P., Zhu, C., Gao, G., Xiao, K., Sun, H., Zheng, S., Liang, Y., Jiang, G., 2015. Occurrence of organochlorine pesticides in the environmental matrices from King George Island, west Antarctica. Environ. Pollut. 206, 142-149.

Zhao, Y., Huang, T., Wang, L., Gao, H., Ma, J., 2015. Step changes in persistent organic pollutants over the Arctic and their implications. Atmos. Chem. Phys. 15 (1) 1225-1267. 